\title{
Mechanical Stabilization of BSCCO-2223 Superconducting Tapes
}

\author{
Christopher G. King, Delton A. Grey and Anthony Mantone \\ GE Medical Systems, Florence, SC 2950 I, USA \\ Kenneth G. Herd and E.Trifon Laskaris \\ GE Corporate Research and Development, Schenectady, NY 12309, USA
}

\begin{abstract}
A system to provide mechanical stabilization to high temperature BSCCO-2223 superconducting tape by laminating $0.081 \mathrm{~mm}$ thick, spring hard, copper foil to both sides with leadtin eutectic solder has been successfully optimized. This system has been applied as a method to create a strong, windable composite from pure silver BSCCO tapes with a minimum of critical current $\left(I_{c}\right)$ degradation. The "as received" conductor is evaluated for physical consistency of width and thickness over the 3000 meters that were later strengthened, insulated and wound into a demonstration coil. Electrical degradation in the strengthened tape as a result of lamination was found to average 24 percent with a range from 4 to 51 percent. This was less than the degradation that would have occurred in an unstrengthened tape during subsequent insulation and coil winding processes. Additional work was performed to evaluate the mechanical properties of the strengthened tapes. The copper can double the ultimate tensile strength of the pure silver tapes. Additionally, pure silver and dispersion strengthened silver matrix tapes are laminated with $0.025 \mathrm{~mm}$ thick copper and 304 stainless steel foil to investigate minimization of the cross sectional area of the strengthening component. The stainless steel can increase the UTS of the pure silver tapes sixfold. Metallography is used to examine the laminate and the conductor. Mechanical properties and critical currents of these tapes are also reported both before and after strengthening. The $I_{c}$ is also measured as a function of strain on the laminated tapes.
\end{abstract}

\section{INTRODUCTION}

Advances in the critical current $\left(\mathrm{I}_{c}\right)$, length, and uniformity of properties along the length in high temperature superconconductors (HTS) have allowed magnet and device designers to build demonstration coils. A prototype racetrack coil for a superconducting electrical generator was built by the General Electric Company (GE) for the U. S. Department of Energy (DOE) as part of a demonstration program to investigate a superconducting rotor design. This demonstration coil is presented in a companion paper, these proceedings. $[1,2]$ This coil was fabricated from 2000 meters of pure silver matrix BSCCO-2223 HTS tape manufactured by Intermagnetics General Corporation (IGC).

Due to the high forces in the generator field winding and the inherent weakness of the pure silver matrix, a lamination technique developed at GE for $\mathrm{Nb}_{3} \mathrm{Sn}$ tape was successfully applied to strengthen the HTS tapes.[3, 4, 5] Relatively thick, $0.081 \mathrm{~mm}$ by $3.0 \mathrm{~mm}$ wide, spring hard copper foils were

\footnotetext{
Manuscript submitted August 27, 1996.

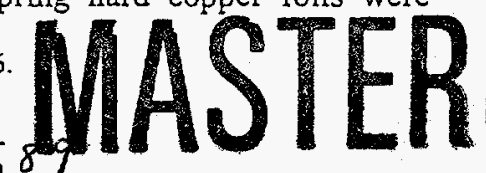

laminated to the conductor. The physical, mechanical and electrical properties of the HTS tapes used in the demonstration coil, both before and after strengthening, are reported. The evolution of the process to laminate pure silver matrix HTS tapes with a minimum of electrical property degradation is described.

Maximization of the coil current density $\left(J_{c}\right)$ through minimization of the cross sectional area of the stabilizing and strengthening components of the HTS tape is also explored in this paper. Pure silver and dispersion hardened silver matrix HTS tapes are laminated with thin, $0.025 \mathrm{~mm}$ thick by $4 \mathrm{~mm}$ wide foils of spring hard copper and 304 stainless steel. Mechanical, electrical and strain sensitivity properties of these laminates are characterized.

\section{LAMINATION OF SUPERCONDUCTORS}

It is known that pure silver matrix BSCCO-2223 HTS tapes are highly strain sensitive when compared to conventional $\mathrm{NbTi}$ superconductors. The annealed silver stabilizer used in powder-in-tube BSCCO-2223 tapes provides very little strength to the conductor. As a result, the winding tension for the bare conductor must be limited to $0.5 \mathrm{~kg}$. This low level of tension is barely practical for the manufacture of solenoidal windings, and is insufficient for racetrack geometries due to the sagging of the straight sections. Low winding tension also greatly increases the risk of conductor buckling in the lower layers as the winding progresses.

The need to laminate spring hard copper foils to $\mathrm{Nb}_{3} \mathrm{Sn}$ tape, to provide stabilizer and mechanical support of the britthe A-15 superconductor, resulted in the development of the lamination system at GE.[4] This equipment has been modified to accept the pure silver matrix BSCCO-2223 HTS tapes.

\section{CONDUCTOR STRENGTHENING PROCESS OPTIMIZATION}

Initially, an iterative process optimization cycle of lamination, determination of electrical degradation using long length $\mathrm{I}_{\mathrm{c}}$ testing of the strengthened HTS tape at 0 Tesla (T) and 77 Kelvin (K), and tooling refinement was followed. In the first trial, spring hard, pretinned copper foil, $0.081 \mathrm{~mm}$ thick by $25.4 \mathrm{~mm}$ wide, was slit to $3 \mathrm{~mm}$ widths and laminated to both sides of the BSCCO-2223 tape using the lamination parameters shown in Table $I$. Full length $I_{c}$ testing showed that the tape had lost 80 to 100 percent of the total Ic availible prior to the lamination process when tested at $0 \mathrm{~T}$ and $77 \mathrm{~K}$.

DISTRIBUTION OF THIS DOCUMENT IS UNUIMITED 


\section{DISCLAIMER}

This report was prepared as an account of work sponsored by an agency of the United States Government. Neither the United States Government nor any agency thereof, nor any of their employees, make any warranty, express or implied, or assumes any legal liability or responsibility for the accuracy, completeness, or usefulness of any information, apparatus, product, or process disclosed, or represents that its use would not infringe privately owned rights. Reference herein to any specific commercial product, process, or service by trade name, trademark, manufacturer, or otherwise does not necessarily constitute or imply its endorsement, recommendation, or favoring by the United States Government or any agency thereof. The views and opinions of authors expressed herein do not necessarily state or reflect those of the United States Government or any agency thereof. 


\section{DISCLAMMIER}

Portions of this document may be illegible in electronic image products. Images are produced from the best available original document. 


\section{CONDUCTOR FOR THE GENERATOR FIELD WINDING}

In all, 3300 meters of HTS tape were sent from IGC to GE for the generator coil project. During processing at GE, about 500 meters of tape were consumed in lamination process optimization trials, 2800 meters were laminated and insulated. The insulation process longitudinally wraps paper around the tape continuously with a glue line holding down the overlap. This insulation provides turn to turn insulation in the coil and is more completely described in an earlier paper.[3] The only problem encountered was that the insulation tooling had to be reshimmed for every length due to the rather large variation in the "as received" tape width. Over 2500 meters were chosen for coil winding after $I_{c}$ degradation testing and approximately 2000 meters were wound into the coil. An average of 5 percent of the conductor length was lost in the lamination process due to end effects and in a few cases, up to 18 percent of the length was lost due to process mishaps.

After lamination and insulation, every tape length was returned to IGC for $I_{c}$ degradation measurement. This measurement was performed at $77 \mathrm{~K}$ and $0 \mathrm{~T}$ as in the process optimization trials, but without voltage taps every 10 meters. In the conductor wound into the coil, the starting $I_{c}$ of the lengths averaged 23.7 amps, ranging from a high of 29.2 to a low of $16.8 \mathrm{amps}$, fig. 3. This material, although the variation is fairly high, fits within the range of 15 to $30 \mathrm{amps} \mathrm{I}_{c}$ at $77 \mathrm{~K}$ and $0 \mathrm{~T}$ requested for this project. This range is fairly broad, but was adequate for the requirements of the coil and accounted for the variability due to high strain sensitivity in the pure silver matrix tapes.

Following the processing at $\mathrm{GE}$, the lengths of conductor wound into the coil were found to have an average $I_{c}$ of 17.74 amps, ranging from a high of 24.0 to a low of 12.8 amps, fig. 4. Assuming a 0 to 35 percent reduction in $I_{c}$ would occur in the material due to processing, as was shown in the process optimization trials, the acceptable lower range for $I_{c}$ in the strengthened tapes was lowered to 10 amps. In fig. 5 , it is shown that the actual percent reduction in $I_{c}$ due to strengthening averaged 23.7 percent, but the range was fairly broad from a low of 4 percent to a high of 49 to 51 percent for two lengths. In fig. 6 , percent degradation is graphed as a function of "as received" $I_{c}$. It appears that there are two distinct degradation behaviors based on the initial $I_{c}$ of the tape. Tapes with starting $I_{c}$ 's greater than 25 amps appear to have a much greater scatter in degradation than tapes with starting $I_{c}$ 's less than 25 amps. A one-way analysis of variance (ANOVA) was performed the tapes by identifying the two populations with starting $I_{c}$ 's above and below 25 amps. This analysis shows statistically, that two distinct behaviors do occur. Tapes with "as received" $I_{c}$ 's greater than 25 amps have an average of nearly 32 percent degradation with one standard deviation of 11.8 percent. Tapes with "as received" $I_{c}$ 's of less than 25 amps have an average degradation of almost 15 percent with a standard deviation of only 6.6 percent. Higher scatter in the $I_{c}$ performance of very high $\mathrm{J}_{\mathrm{c}}, \mathrm{Nb}_{3} \mathrm{Sn}$ tapes has been noted in the development cycle of the $\mathrm{Nb}_{3} \mathrm{Sn}$ tape facility at GE. [7]

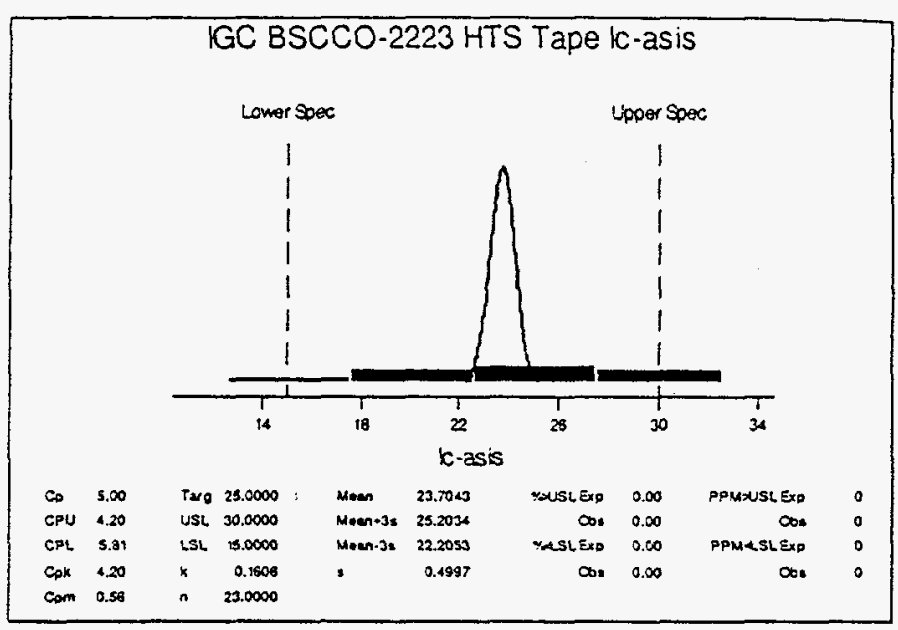

Fig. 3. Process capability analysis of "as received" $I_{c}$ at $77 \mathrm{~K}$ and $0 \mathrm{~T}$ for HTS tape.

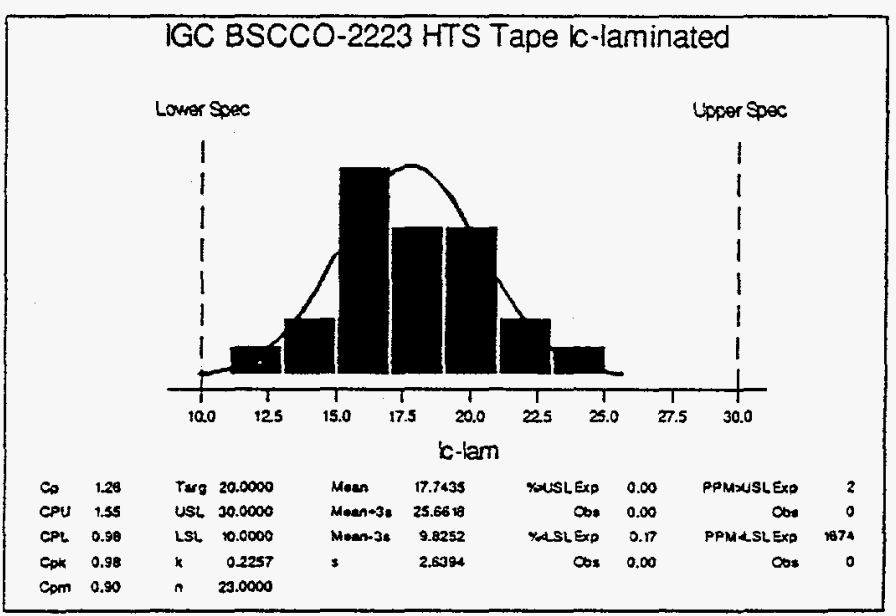

Fig. 4. Process capability analysis of $I_{c}$ at $77 \mathrm{~K}$ and $0 \mathrm{~T}$ for laminated HTS tape.

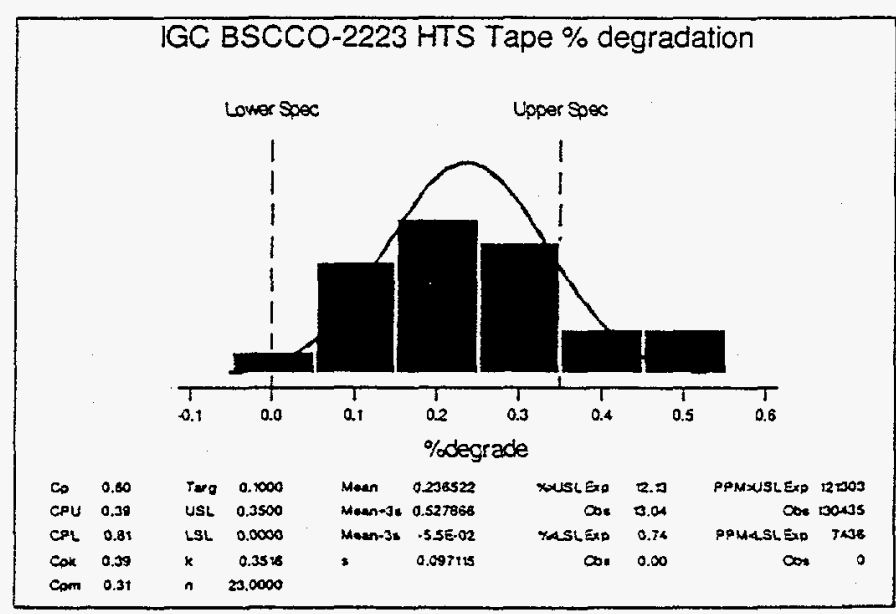

Fig. 5 Process capability analysis of percent degradation in the $I_{c}$ at $77 \mathrm{~K}$ and $0 \mathrm{~T}$ for laminated HTS tape. 
One possible explaination for the degradation was that the tape lost $I_{c}$ as a result of strain sensitivity. The superconductor rollers immersed in the solder only had a $5 \mathrm{~cm}$ diameter which has been shown by Yau [6] to be the minimum diameter for zero loss due to strain sensitivity in a multifilamentary BSCCO-2223 tape. Another possible reason was that the tension along the superconductor path was too high and exceeded the axial strain limits of the tape.

A second trial was conducted with $8 \mathrm{~cm}$ diameter superconductor rollers and with reduced line tensions and closure pressures, Table I. These lamination parameters reduced the degradation to an average of 69 percent with a range along the length of 52 to 73 percent, fig. 1 .

The most vulnerable point in the process was determined to be where the pure silver matrix tape was suspended between rollers leading up to the lamination tooling, unsupported, with a back tension from the payoff spool. Between the back tension and the weight of the tape over this 5 meter span, it was possible that the axial strain limits of the tape were still being exceeded. Therefore, the superconductor payoff was refixtured and placed directly above the lamination tooling and the back tension on the spool was completely eliminated so that the superconductor could literally fall into the solder bath as the process pulled it off of the spool.

A third trial was conducted with the refixtured, low tension superconductor payoff and further reduced line tensions and closure pressures, Table I. The superconductor payoff was allowed to freewheel. Post lamination Ic testing of the 80 meter length showed that degradation was reduced to an average of 29 percent with a range along the length of 20 to 43 percent, fig. 1.

A fourth trial was conducted on two consecutive lengths of tape. Payoff settings remained the same as in the third trial, Table 1. The closure pressure was reduced further to 4.2 $\mathrm{MN} / \mathrm{m}^{2}$, yielding a process tension on the laminate of $0.55 \mathrm{~kg}$ and a spooling tension of $0.70 \mathrm{~kg}$. These two lengths, 130 and

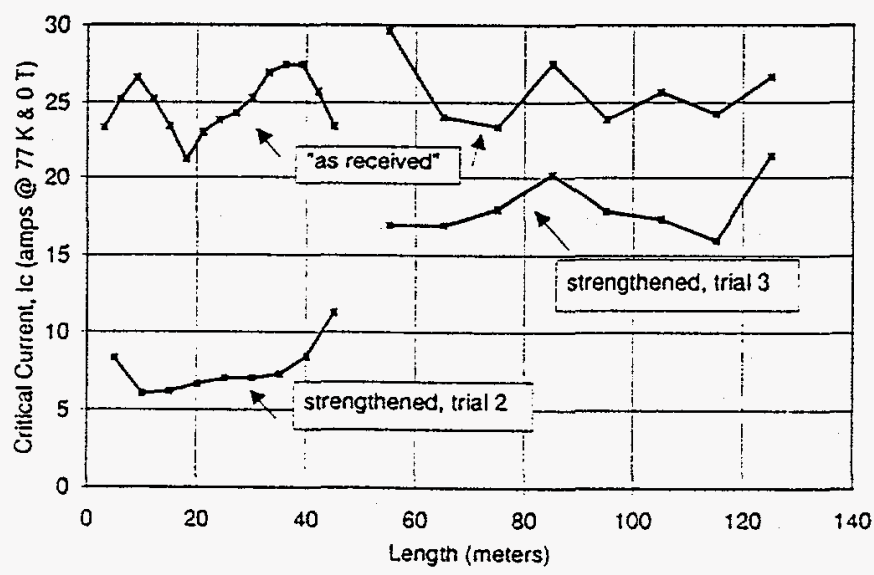

Fig.1. $I_{c}$ degradation due to lamination resulting from the process parameters of the second and third trial.
TABLE I.

SUMMARY OF PARAMETERS USED FOR LAMINATION PROCESS OPTIMIZATION

\begin{tabular}{|c|c|c|c|c|c|}
\hline Parameter & Units & $\begin{array}{c}\text { Trial } \# \\
\text { l }\end{array}$ & $\begin{array}{c}\text { Trial } \\
2\end{array}$ & $\begin{array}{c}\text { Trial \# } \\
3\end{array}$ & $\begin{array}{c}\text { Trial } \# \\
4\end{array}$ \\
\hline $\begin{array}{c}\text { Cu Payoff } \\
\text { Tension }\end{array}$ & $\mathrm{kg}$ & .45 & .21 & .11 & .11 \\
\hline $\begin{array}{l}\text { SC Payoff } \\
\text { Tension }\end{array}$ & $\mathrm{kg}$ & .45 & .18 & $\begin{array}{l}\text { free- } \\
\text { wheel }\end{array}$ & $\begin{array}{l}\text { free- } \\
\text { wheel }\end{array}$ \\
\hline $\begin{array}{l}\text { SC Roller } \\
\text { Diameter }\end{array}$ & $\mathrm{cm}$ & 5.0 & 8.0 & 8.0 & 8.0 \\
\hline $\begin{array}{l}\text { Closure } \\
\text { Pressure }\end{array}$ & $\mathrm{MN} / \mathrm{m}^{2}$ & 26.5 & 14.8 & 5.3 & 4.2 \\
\hline $\begin{array}{l}\text { Process } \\
\text { Tension }\end{array}$ & $\mathrm{kg}$ & 2.31 & 1.27 & 1.05 & .55 \\
\hline $\begin{array}{l}\text { Spooling } \\
\text { Tension }\end{array}$ & $\mathrm{kg}$ & 2.50 & 1.50 & 1.27 & .70 \\
\hline $\begin{array}{l}\text { Ic Degra- } \\
\text { dation }\end{array}$ & percent & $80-100$ & $\begin{array}{l}52-73, \\
\operatorname{avg}=69\end{array}$ & $\begin{array}{c}20-43 \\
\mathrm{avg}=29\end{array}$ & $\begin{array}{c}9-18 ; 13 \\
16-36 ; 29\end{array}$ \\
\hline
\end{tabular}

100 meters long, had $I_{c}$ degradation averaging 13 percent ranging from 9 to 18 percent along the length for the $130 \mathrm{~m}$ piece and averaging 29 percent ranging from 16 to 36 percent along the length for the 100 meter piece, fig. 2.

At this point, this amount of electrical degradation was determined to be less than the degradation that an unstrengthened conductor would experience during the insulation and coil winding processes. Since unwinding and rewinding of the strengthened tapes showed no additional degradation, it was decided to laminate the conductor for the generator coil.

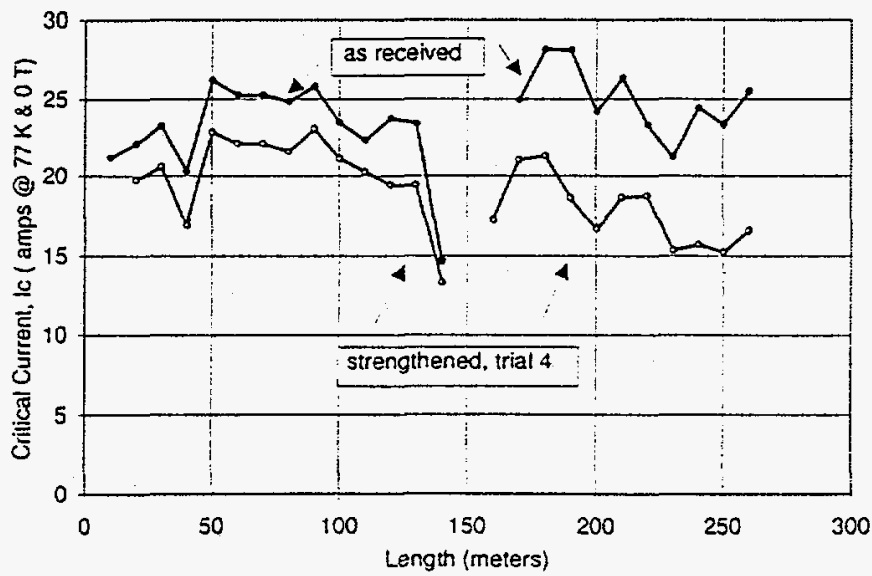

Fig.2. $I_{c}$ degradation due to lamination on two consecutive lengths resulting from process parameters of the fourth trial. 


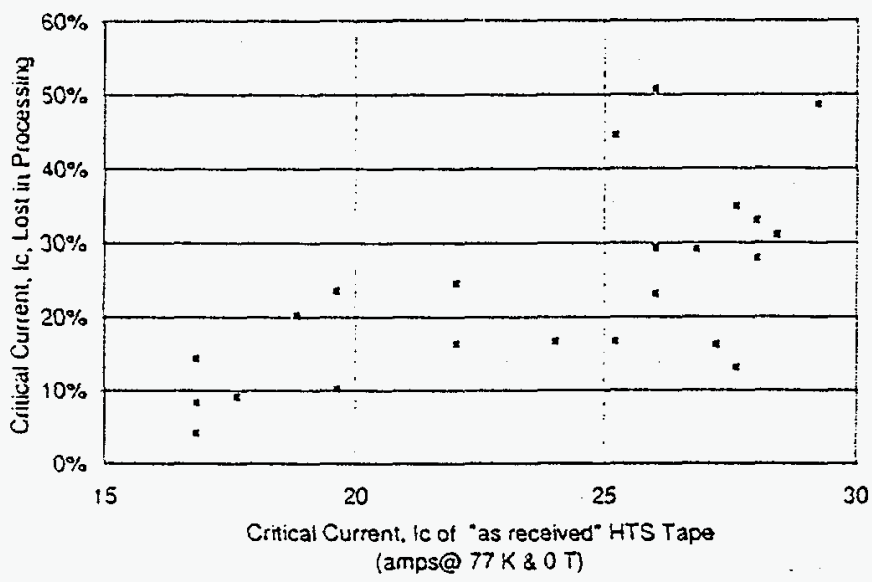

Fig. 6. Graph of percent degradation in $I_{c}$ due to lamination as a function of the "as received" $I_{c}$ of the HTS tape.

\section{STRENGTHENER CROSS SECTIONAL AREA MINIMIZATION}

A major problem with the strengthening technique described in the previous sections is that the two $0.081 \mathrm{~mm}$ thick by $3 \mathrm{~mm}$ wide copper foils increase the cross sectional area of the HTS tape by 67 percent, decreasing overall conductor $J_{c}$ by an equal amount. In this experiment, $0.0254 \mathrm{~mm}$ thick by $4 \mathrm{~mm}$ wide foils of copper and 304 stainless steel (304SS) were procured and laminated to HTS tape from IGC with a pure silver matrix, $0.254 \mathrm{~mm}$ thick by $4.06 \mathrm{~mm}$ wide, and to HTS tape from American Superconductor Corporation (ASC) with a high strength silver matrix, $0.254 \mathrm{~mm}$ thick by $4.32 \mathrm{~mm}$ wide. Fig. 7 shows metallographic cross section of HTS tapes laminated with (a) $0.081 \mathrm{~mm}$ thick and with (b) $0.0254 \mathrm{~mm}$ thick strengthening foils. Room temperature tensile testing of the "as received" and laminated materials are shown in Table II. The most notable result is the 4.6 times increase in UTS for the IGC tape when laminated with the 304SS. The ASC tape, already prestrengthened by the bigh strength silver matrix, increases UTS by 85 percent, from 124 to $230 \mathrm{MN} / \mathrm{m}^{2}$, when laminated with the 304SS.

Strain sensitivity testing results of the $I_{e}$ of the "as received" and laminated IGC and ASC tapes, are shown in figs. 9 and 10 , respectively. Strain sensitivity and load prior to $I_{c}$ degradation are improved with the copper and the stainless steel for the IGC tape. There is a minimum of a three times increase in the load carrying ability and a two times increase in the strain where $I_{c}$ degradation occurs in the IGC HTS tape laminated with $0.0254 \mathrm{~mm}$ thick copper over the "as received" tape. There is a minimum of a four times increase in the load carrying ability and nearly a three times increase in the strain where $I_{c}$ degradation occurs in the IGC HTS tape laminated with $0.0254 \mathrm{~mm}$ thick $304 S S$ foils. In the ASC tape, the load carrying ability prior to loss in $I_{c}$ is almost doubled to $210 \mathrm{MN} / \mathrm{m}^{2}$ with the $304 \mathrm{SS}$ foil lamination, but strain sensitivity is degraded slightly from 0.55 to 0.47 percent. ASC tape laminated with copper was not tested.
TABLE II

ULTIMATE TENSILE STRENGTH AND PERCENT ELONGATION AT ROOM TEMPERATURE FOR THE “AS RECEIVED” AND LAMINATEO MATERIALS

\begin{tabular}{|c|c|c|c|c|c|}
\hline conductor & $\begin{array}{l}0.081 \\
\mathrm{~mm} \mathrm{Cu}\end{array}$ & $\begin{array}{l}0.0254 \\
\mathrm{~mm} \mathrm{Cu}\end{array}$ & $\begin{array}{l}0.0254 \\
\mathrm{~mm} 304 \\
\mathrm{SS}\end{array}$ & $\begin{array}{l}\text { IGC- } \\
\text { HTS } \\
\text { pure } \\
\text { silver } \\
\text { matrix }\end{array}$ & $\begin{array}{l}\text { ASC- } \\
\text { HTS } \\
\text { high } \\
\text { strength } \\
\text { matrix }\end{array}$ \\
\hline $\begin{array}{l}\text { as received } \\
\left(\mathrm{MN} / \mathrm{m}^{2}\right) \\
(\% \text { elong })\end{array}$ & $\begin{array}{l}427 \\
2.0\end{array}$ & $\begin{array}{l}451 \\
2.1\end{array}$ & $\begin{array}{l}1090 \\
2.7\end{array}$ & $\begin{array}{l}42 \\
1.5\end{array}$ & $\begin{array}{l}124 \\
8.6\end{array}$ \\
\hline $\begin{array}{l}\text { laminated } \\
\text { with } 0.08 ! \\
\text { mu Cu }\end{array}$ & $n / a$ & $\pi / a$ & $\mathrm{n} / \mathrm{a}$ & $\begin{array}{l}162 \\
3.0\end{array}$ & $\begin{array}{l}159 \\
8.3\end{array}$ \\
\hline $\begin{array}{l}\text { laminated } \\
\text { with } 0.0254 \\
\mathrm{~mm} \mathrm{Cu}\end{array}$ & $\mathrm{n} / \mathrm{a}$ & $n / a$ & $\Omega / a$ & $\begin{array}{l}73 \\
3.0\end{array}$ & $\begin{array}{l}126 \\
7.8\end{array}$ \\
\hline $\begin{array}{l}\text { laminated } \\
\text { with } 0.0254 \\
\mathrm{~mm} 304 \text { SS }\end{array}$ & $\mathrm{w} / \mathrm{a}$ & $\mathrm{n} / \mathrm{a}$ & $\mathrm{n} / \mathrm{a}$ & $\begin{array}{l}193 \\
2.7\end{array}$ & $\begin{array}{l}230 \\
4.1\end{array}$ \\
\hline
\end{tabular}
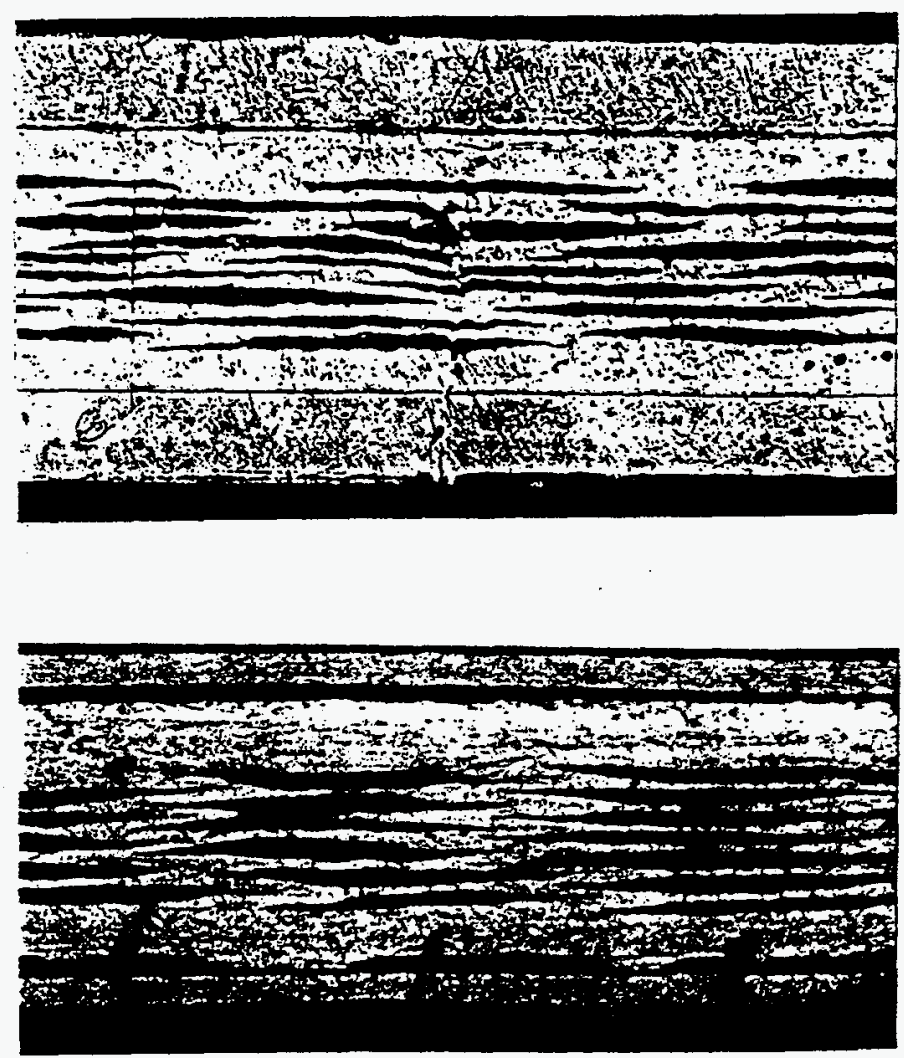

Fig 7. Metallography of HTS tapes laminated with (a) 0.081 and (b) $0.0254 \mathrm{~mm}$ strengthening foils. 


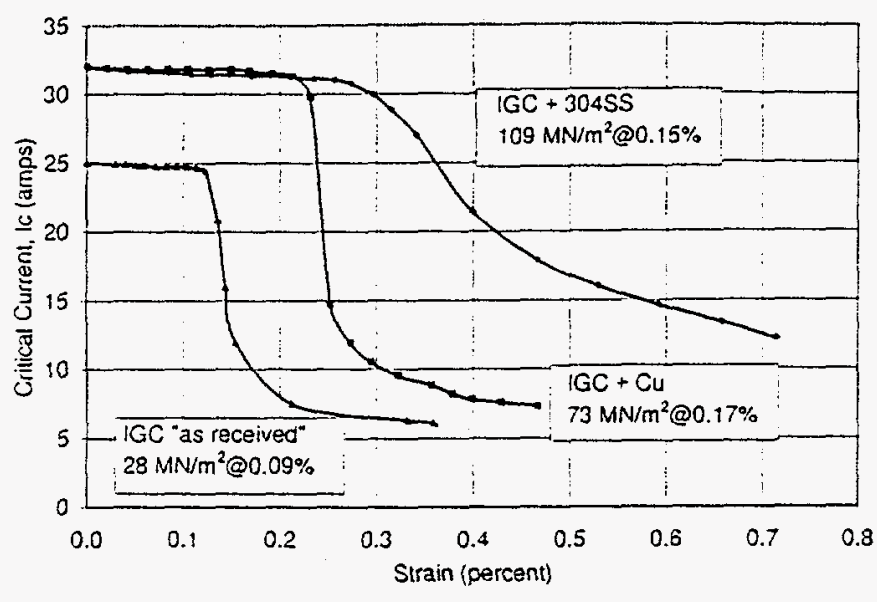

Fig. 8. $I_{c}$ at $77 \mathrm{~K}$ and $0 \mathrm{~T}$ versus strain sensitivity measurements for IGC "as received and laminated with $0.0254 \mathrm{~mm}$. 304Stainless steel and copper foil.

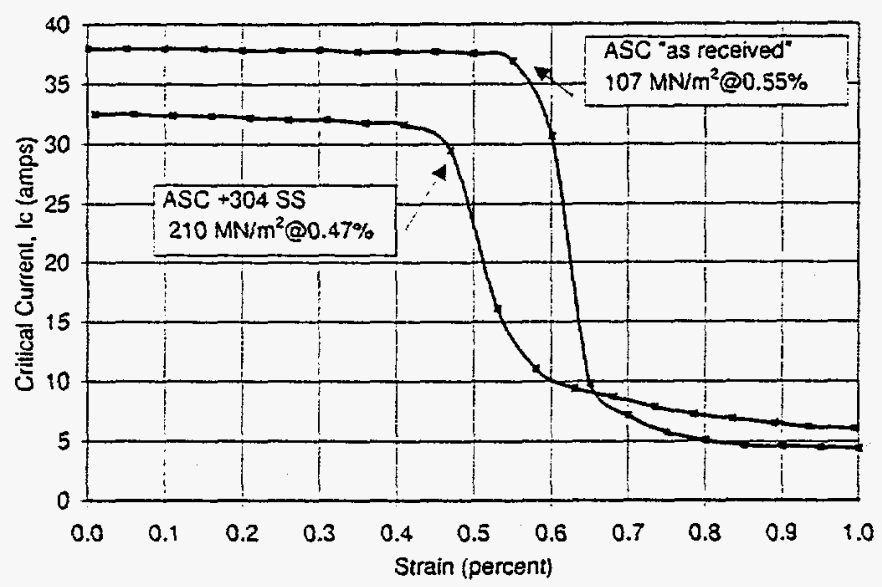

Fig. 9. $I_{c}$ at $77 \mathrm{~K}$ and $0 \mathrm{~T}$ versus strain sensitivity measurements for ASC "as received and laminated with $0.0254 \mathrm{~mm}$ 304Stainless steel foil.

\section{CONCLUSIONS}

A system to provide mechanical stabilization to high temperature BSCCO-2223 superconducting tape by laminating $0.081 \mathrm{~mm}$ thick, spring hard, copper foil to both sides with lead-tin eutectic solder has been successfully optimized. Maximization of roller diameters and minimization of line tensions to stay below bend and axial strain limits of the HTS tape were key parameters in making this process work. Over 3300 meters of HTS tape from IGC was strengthened by this lamination process and subsequently wound into a demonstration coil for DOE. Initial testing to laminate thinner materials to HTS tapes to minimize strengthener cross sectional area while maximizing strength has yielded promising results. This lamination process is useful in making strain sensitive HTS materials easier to use and more robust in the manufacture of electromagnetic devices.

\section{ACKNOWLEDGEMENT}

The authors wish to thank Pradeep Haldar and Jamie Hoehn of Intermagnetics General Corporation, John Scudiere and Dave Buczek of American Superconductor Corporation, and Mas Suenaga of Brookhaven National Laboratories for supplying samples and testing of the BSCCO-2223 HTS tapes described in this paper. Also, from GE Medical Systems, the assistance of Clyde Gouldsberry for tooling development, John Book for lamination, Randy Dennis for lamination and insulation process development, Frank Shaffer for respool, and $\mathrm{O}^{\prime} \mathrm{Neil} \mathrm{McClam}$ for other process assistance is sincerely appreciated.

\section{REFERENCES}

[1] K. Lay, K. Herd, C. King, "A 100MVA Generator Utilizing High Tem perature Superconducting Windings: Design Assessment and Component Development," Intemational Cryogenic Materials Conference, Colum bus, OH, 1995.

[2] K. G. Herc, L. Salasoo, E. T. Laskaris, R. A. Ranze, C. G. King, P. Haldar, J. G. Hoehn, "Development and Fabrication of a Bi-2223 Racetrack Coil for Generator Applications," Applied Superconductivity Conference, Pittsburgh, PA, 1996.

[3] C. King, K. Herd, T. Laskaris, A. Mantone, "Evaluation of a Strengthen ing and Insulation System for High Temperature BSCCO-2223 Super conducting Tape," Intemational Cryogenic Materials Conference, Colum bus, OH, 1995.

[4] C. G. King, G. S. Kobus, A. Mantone, M. L. Dennis, F.D. Shaffer, R. A. Stephens, N. G. Fiddes, "Method and Apparans for Laminating Foils into a Superconducting Tape for use in a Superconducting Magner, U. S. Patent \# 5,299,728, April 5, 1994.

[5] M.G.Benz, "Mechanical and electrical properties of diffusion-processed $\mathrm{Nb3Sn-Copper-Stainless} \mathrm{Steel} \mathrm{composite} \mathrm{conductors",} \mathrm{Joumal} \mathrm{of}$ Applied Physics, Vol. 39, No. 6, 2533-2537, May 1968.

[6] J.Yau, N.Savvides, "Strain Tolerance of Multifllament Bi-Pb-Sr-CaO/Silver Composite Superconducting Tapes," Applied Physics Letters, 65 (11) 1454-1456 September 1994.

[7] GE Nb3 Sn Tape Design Review, March, 1991. 